\title{
HISTORICISMO, NAÇÃO E RAÇA: A CONSTRUÇÃO DA HISTÓRIA-DISCIPLINA E AS EXCLUSÕES GEOPOLÍTICAS DA RAZÃO
}

\author{
Historicism, nation and race: the construction of history-discipline and the geopolitical \\ exclusions of reason
}

Eduardo Antônio Estevam Santos*

Resumo: O presente artigo justifica-se pelo exercício moderno de constante revisão crítica do fazer/saber histórico, e uma vez que os estudos sobre raça e nação apresenta-se no mundo contemporâneo como elemento chave para a compreensão dos fenômenos multifacetados das transformações sociais, políticas e culturais, este trabalho, apresenta os entrelaçamentos entre nacionalismo e raça na construção da história-disciplina no século XIX em seus aspectos políticos e epistemológicos. Temos como objetivo, demonstrar as impossibilidades de estudo histórico do continente africano em função das exclusões da razão.

Palavras-chave: Historicismo, Razão, Raça, África, Nação.

\begin{abstract}
This article is justified by the modern exercise of a constant critical review of historical knowledge and practice, and since studies on race and nation have been presented in the contemporary world as a key element for understanding the multifaceted phenomena of social, political and This work presents the interweaving between nationalism and race in the construction of history-discipline in the nineteenth century in its political and epistemological aspects. We have as objective, to demonstrate the impossibilities of historical study of the African continent in function of the exclusions of reason.
\end{abstract}

Keywords: Historicism, Reason, Race, Africa, Nation.

O artigo discute os sentidos possíveis de um historicismo codificado racialmente em seus dispositivos de racionalidade, uma vez que, tem sido corrente o interesse dos historiadores sobre os avanços significativos desta corrente histórica, a respeito dos seus interesses vinculados aos poderes dominantes ou até mesmo sobre o seu caráter conservador ou revolucionário. Procurarei argumentar também, sobre as antinomias presentes em suas concepções de nação e documento histórico, para poder extrair o seu caráter raciológico em seus procedimentos e métodos inovadores.

O século XIX, incontestavelmente, foi o século da história. Debates em torno da verdade, do estatuto de ciência, dos fatos, dos métodos, das técnicas e dos documentos enriqueceram profundamente a história-disciplina. Para François Dosse ${ }^{1}$ foi o momento em que

\footnotetext{
${ }^{*}$ Doutor em História Social pela Pontifícia Universidade Católica de São Paulo (PUC-SP). Professor do Instituto de Humanidades e Letras da Universidade da Integração Internacional da Lusofonia Afro-brasileira. E-mail: eduardoestevame@unilab.edu.br.

${ }^{1}$ DOSSE, François. A História. São Paulo: Editora Unesp, 2012, p.37.
} 
o gênero histórico se profissionalizou, dotando-se de métodos, regras, ritos e modos particulares de entronização e de reconhecimento. Mesmo reconhecendo os padrões modestos das ciências humanas e sociais do século XIX, para Eric Hobsbawm², ela foi uma disciplina retrógrada. Hobsbawm, ao procurar apontar as contribuições do marxismo para a história como uma alternativa mais produtiva de investigação do passado humano, em seu ensaio $\mathrm{O}$ que os historiadores devem a Karl Marx?, argumenta que as contribuições do século XIX ao entendimento da sociedade humana, passada e presente, eram insignificantes e ocasionais.

Para alguns pesquisadores o historicismo foi um método, para outros uma teoria da ciência histórica, para nós, um conjunto de todos esses elementos acrescentado de uma visão de mundo fundada metafisicamente, com implicações políticas. As diferentes concepções provam que o historicismo não comporta uma acepção unívoca. Uma de suas características centrais foi à rejeição do universalismo da ilustração, substituída pela visão de que cada nação ${ }^{3}$ era considerada como uma totalidade orgânica com suas leis próprias de evolução. Para Adam Schaff $^{4}$, em História e Verdade, o historicismo foi uma tendência para captar a natureza, a sociedade e o homem em constante movimento, nas suas mutações contínuas. Schaff, observa ainda que esses historiadores apreendiam a realidade como dinâmica e evolutiva, de forma que, os objetos, a natureza, as ideias e as estruturas evoluiriam com a história. O objetivo era captar o mundo como movimento e mudança, leia-se o mundo europeu.

José D’Assunção Barros ${ }^{5}$ em seu artigo Historicismo: notas sobre um paradigma, aponta que essa corrente histórica em seus primórdios deve ser entendida em sua relação direta com o contexto de afirmação dos estados nacionais, pois, havia um grande interesse da burocracia estatal no financiamento de projetos historiográficos. Analisando numa perspectiva histórica mais ampla, a afirmação e consolidação dos estados nacionais na Europa deu-se a partir do encontro da África com imperialismo colonial, e como bem enfatiza o africanista $\mathrm{M}^{\prime} \mathrm{BOKOLO}^{6}$, o imperialismo colonial diz mais respeito à história e a historiografia europeia do que a história da África propriamente dita. Ainda que as fronteiras coloniais no continente africano tenham se definido nas décadas de 1880 e 1890, o colonialismo na África foi cumulativo. Os nacionalismos e chauvinismos europeus foram uma das alavancas para a afirmação/consolidação dos estados nacionais. Os nacionalismos eram uma verdadeira

\footnotetext{
${ }^{2}$ Ver HOBSBAWM, E. J. Sobre História. São Paulo: Editora Companhia de Bolso, 1988.

${ }^{3}$ Ver FONTANA, Josep. A história dos homens. São Paulo: Edusc, 2004, p. 223.

${ }^{4}$ SCHAFF, Adam. História e Verdade. São Paulo: Martins Fontes, 1983, pp. 188-189.

${ }^{5}$ BARROS, José D’Assunção. Historicismo: notas sobre um paradigma. Revista Antítese, v.5, n. 9, pp. 391-419, jan/jul, 2012.

${ }^{6}$ M’BOKOLO, Elikia. África Negra - História e Civilizações. Tradução de Alfredo Margarido. Salvador: EDUFBA; São Paulo: Casa das Áfricas, 2009, p. 307-314.
} 
campanha política, as ligas nacionalistas exaltavam a "maior Inglaterra", a "maior Alemanha", "a maior França", o ideal de grandeza estava necessariamente acompanhado da posse de um império, as aspirações imperialistas estavam presentes nestas práticas políticas.

Johann Gottfried Herder (1744-1803) foi o principal expoente do historicismo alemão, considerado precursor entre os historiadores românticos, em sua obra Fragmentos sobre a literatura alemã escrito em 1766 propõe uma investigação histórica para se alcançar uma literatura autenticamente nacional. Os historicistas alemães propunham elaborar uma história particularista, nacional, eram contrários aos universalismos abstratos de inspiração iluminista.

Terá alguma nação coisa mais preciosa [que a língua de seu país]? Partindo do estudo das literaturas nativas, temos aprendido a conhecer épocas e povos mais profundamente que ao longo do triste e decepcionante caminho da história política e militar. Nesta última, raramente é possível ver nada que não seja a forma em que o povo foi dominado, como ele se deixou massacrar, na primeira, aprendemos como esse povo pensava, quais eram seus anseios e desejos, como apreciava seus prazeres, de que maneira era dirigido por seus mestres ou suas inclinações ${ }^{7}$.

Leopold von Ranke foi um funcionário ideológico do estado prussiano, útil, serviçal e consciente do papel que lhe correspondia desempenhar ${ }^{8}$, era um homem político, fazia sempre referência ao poder e admirava os dirigentes, foi amigo de Frederico Guilherme da Prússia e de Maximiliano da Baviera, dirigiu a Revista história-política, publicada pelo governo, numa conjuntura histórica em que "a atividade dos homens canaliza-se através das nações, que são o componente fundamental da sociedade ${ }^{9} "$. Seus livros, aponta Fontana, falam sempre dos estados e das relações que se estabelecem entre eles por meio da diplomacia e da guerra. Ele era contrário à ideia de nação que baseava-se em critérios étnicos e culturais, sua concepção de nação era de povos, no sentido de coletividades humanas interclassistas, fundamentadas no sentimento da nacionalidade compartilhada ${ }^{10}$. Fizeram escola com Leopold von Ranke (17951886), Jacob Burckhartdt (1818-1897), Johan Gustav Droysen (1808-1884) e Theodor Mommsen (1817-1903).

Para os pesquisadores historicistas, influenciados pelo espírito da ilustração, até então, não existia nenhum estudo sistemático sobre as mudanças ocorridas ao longo do tempo, o que constituiria o verdadeiro objetivo do historiador, fazia-se necessário, a exemplo dos estudos que realizaram com a língua, analisar as diferentes temporalidades em direção a construção de uma cultura nacional. Esse novo saber/fazer histórico apresentava o processo de reconstrução do

\footnotetext{
${ }^{7}$ Ver PIRES, Débora Castanheira. O nacionalismo pré-romantico de Herder. Monografia. Pontifícia Universidade da Católica do Rio de Janeiro, Rio de Janeiro, 2009, p.36.

${ }^{8}$ FONTANA, Josep. A história dos homens... Op. cit., p. 227.

${ }^{9}$ Idem.

${ }^{10}$ FONTANA, Josep. A história dos homens... Op. cit., p. 228.
} 
passado por um procedimento crítico. O exame das fontes, quer fossem do passado mais remoto ou dos períodos menos recuados em relação ao presente do historiador por meio do método crítico, foi um ponto capital para o historicismo. Para José D’Assunção Barros, "somente com o pleno exercício deste procedimento crítico a história poderia começar a aprender a ser moderna ${ }^{11}$ ", mas, acreditamos que se ampliarmos esse procedimento para além do espaçotempo europeu iremos reconhecer em Ibn Khaldun (1332-1406) a tradição historiográfica de uma rigorosa metodologia de análise histórica, presente em sua obra Muqaddimah (Os prolegômenos).

Para o historiador inglês J. D. Fage, em A evolução da historiografia da África, a modernização da disciplina histórica fez com que o passado africano antes do início do imperialismo europeu só pudesse ser reconstituído por arqueólogos, linguistas e antropólogos, uma vez que a natureza de suas fontes - testemunhos dos restos materiais, linguagem e os costumes primitivos - eram coisas que não diziam respeito aos historiadores ${ }^{12}$. Sabemos que história é a memória dos povos e que a natureza do seu registro possui diferentes linguagens, e ainda, não é possível ser encontrado os mesmos tipos de documentos na Europa ${ }^{13}$ e na África. Não se trata de reduzir a importância da contribuição original do historicismo - a aplicação de um rigoroso método de crítica documental - mas, dos seus aspetos racionalistas e etnográficos, o que produziu um verdadeiro feitichismo pelo documento escrito. Essas críticas também estão presentes nos ensaios do renomado historiador Eric Hobsbawm ${ }^{14}$, quando tece suas observações sobre a discussão documental e os procedimentos metodológicos dessas escolas oitocentistas, leia-se historicismo. O contributo dessas correntes historiográficas, apenas se aplicava a uma classe limitada de fenômenos históricos, "porque aceitava acriticamente certos fenômenos como dignos de estudo especial enquanto outros não ${ }^{15}$ ".

É importante salientar que os primeiros trabalhos sobre a história da África são tão antigos quanto o início da história escrita, e a história do norte da África continuou a ser parte essencial dos estudos históricos até a expansão do Império Otomano no século XVI ${ }^{16}$. Após a expedição de Napoleão Bonaparte ao Egito em 1798 o norte da África voltou a ser um campo de estudos que os historiadores não podiam mais negligenciar, observa Fage. No século XIX

\footnotetext{
${ }^{11}$ BARROS, José D’Assunção. Historicismo: notas sobre um paradigma... Op. cit., p. 398.

12 FAGE, J. D. A evolução da historiografia da África. In: História Geral da África, vol.1. São Paulo: Editora Ática, 1982, p. 50-51.

${ }^{13} \mathrm{Ki}$-ZERBO, J. O lugar da história na sociedade africana. In: História Geral da África, vol. 1. São Paulo: Editora Ática, 1982, p. 23.

${ }^{14}$ HOBSBAWM, E. J. Sobre História. São Paulo: Editora Companhia de Bolso, 1988, p. 156.

15 Idem.

${ }^{16}$ FAGE, J. D. A evolução da historiografia da África... Op. cit. p. 42.
} 
com a expansão do poder colonial europeu na África o ponto de vista colonialista passou a dominar os trabalhos sobre a história da porção norte da África e os relatos de viagem constituíram importantes fontes de estudos para os historiadores oitocentistas. Mary Louise Pratt, em Os olhos do império - relatos de viagem e transculturação ${ }^{17}$, demonstrou que os "olhos do império", ou seja, o olhar do homem branco estava representado no olhar dos viajantes, através do imaginário e das representações do real, que ajudaram a construir uma nova consciência planetária ao desbravar o interior da África.

No século XIX também se revelam os historiadores africanos. O reverendo Samuel Johnson, filho de pais escravizados e educado por ingleses, é considerado o primeiro historiador moderno de origem africana, publicou História dos Yorubás no final do século XIX, em 1895. O livro trata da expansão dessa etnia e consequentemente da construção da ideia de uma nação yorubá, Johnson, também estava na esteira das produções intelectuais que influenciavam os nacionalismos culturais, a exemplo de Herder e Fichte.

Como a África "não possuía movimento"18", "história”, “documentos" dignos de um fazer historiográfico, restava a Antropologia, "que é um método não-histórico de estudar e avaliar as culturas e as sociedades dos povos 'primitivos ${ }^{19}$ ” Richard Burton (1821-1890) é quem de fato leva a cabo essa interpretação. Foi um dos viajantes europeus e contribuiu para a fundação da London Anthropological Society, a futura Royal Anthropological Institute. Em seu livro Mission to Gelele, King of Dahomey (1864) tece análises sobre o lugar do negro na natureza, e não na história, pois o cientificismo racializado projetava os negros/as para as condições infra-humanas. Disse, "o negro coletivamente, não progredirá além de um determinado ponto, que não merecerá consideração; mentalmente ele permanecerá uma criança... ${ }^{20 "}$, houve reações, principalmente do intelectual africano James Africanus Horton, mas tal debate tornou-se marginal na London Anthropological Society.

Desta forma a África torna-se um objeto perdido pela história em função das exclusões da razão, a partir do momento em que a narração dos acontecimentos passados, submetidos à sanção da história-ciência preocupada com a descoberta e interpretação do "real", passou a

\footnotetext{
${ }^{17}$ PRATT, Mary Louise. Os olhos do império: relatos de viagem e transculturação Bauru (SP): EDUSC, 1999, p. 11.

${ }^{18}$ Posição do filósofo alemão G. W. F. Hegel (1770-1881), "A África não é um continente histórico; ela não demonstra nem mudança nem desenvolvimento". Caberia aos europeus à responsabilidade de "salvar" e "integrar" a África à humanidade. REIS, José Carlos. História da consciência histórica ocidental contemporânea - Hegel, Nietzsche, Ricoeur. Belo Horizonte: Autêntica, 2013, p. 94-95.

Um conjunto heterogêneo de autores desde a antiguidade registraram informações, observações, relatos, descrições que revelavam um movimento contínuo (ao contrário das análises de Hegel), as contradições e as peculiaridades históricas do continente africano, Heródoto, Manetão, Plínio, Yakut, Ibn Battuta, Ibn Mohammad, Ibn Khaldun.

${ }^{19}$ FAGE, J. D. A evolução da historiografia da África... Op. cit. p. 50.

${ }^{20}$ Idem.
} 
justificar suas investigações com base nos princípios de exposição da racionalidade técnica. Os historicistas procuravam construir narrativas que promovessem rupturas para "livrar-se de um passado cuja crescente estranheza só poderia ser esclarecida e recuperada pela pesquisa histórica ${ }^{21}$ ".

Todas as narrativas humanas apresentam sentidos históricos e sociais em suas racionalidades. O sentido, como bem enfatiza este ensaio, é mais fundamental que a racionalidade, desta forma Jörn Rüsen corrobora com nossa expectativa ao afirmar que a racionalidade do pensamento histórico pode ser descrita como um modo da constituição de sentido que consiste na forma de comunicação do raciocínio argumentativo ${ }^{22}$. Ao menosprezar os sentidos inerentes à diferença cultural, em termos geopolíticos, as percepções eurocoloniais não permitiam atentar para os estudos de tradições e conceitos de outras culturas possibilitando torná-la autocrítica, ao invés de apresentar contribuições para a ciência histórica puramente paroquiais. O lugar de enunciação de uma operação historiográfica, segundo Michel de Certeau em A escrita da história, de certa forma determina "a produção de sentido 23 ", que é indissociável, em história, do seu lugar e do seu objeto".

Paradoxalmente, estes homens, que se negavam a aceitar a existência de leis históricas gerais acima das realidades nacionais, seriam os criadores de métodos de pesquisa que se difundiram universalmente até serem admitidos como norma científica da profissão... ${ }^{24}$

Neste aspecto as posições de Josep Fontana quanto às contradições dos historicistas constitui o ponto nevrálgico que por ora queremos argumentar. As mudanças inovadoras ou por vezes, meros aperfeiçoamentos em algumas técnicas de pesquisas, empreendidas pelo historicismo ocorrem num contexto bastante favorável, cujas transformações eram bastante dinâmicas e rápidas, Koselleck aponta a Revolução Francesa como elemento propulsor, enquanto José D’Assunção Barros ${ }^{25}$ destaca as inovações tecnológicas, tais como, o barco a vapor, locomotivas, fotografias, telégrafos, telefone, iluminação elétrica e automóveis. Procuro estabelecer uma junção entre os avanços políticos, industriais e tecnológicos europeu com o colonialismo. O imperialismo não surgiu aos contemporâneos apenas como uma política

\footnotetext{
${ }^{21}$ KOSELLECK, Reinhart. Futuro Passado - contribuição à semântica dos tempos históricos. Rio de Janeiro: Editora Contraponto, Editora PUC-RIO, 2006, p. 174.

${ }^{22}$ RÜSEN, J. Razão Histórica - teoria da história: os fundamentos da ciência histórica. Brasília: Editora da Universidade de Brasília, 2011, p. 154.

${ }^{23}$ CERTEAU, Michel de. A escrita da história. Rio de Janeiro: Forense Universitária, 1982, p. 53.

${ }^{24}$ FONTANA, Josep. A história dos homens..., Op. cit., p. 231.

${ }^{25}$ BARROS, José D’Assunção. Historicismo: notas sobre um paradigma... Op. cit., 2012.
} 
externa, como uma diplomacia, mas como uma política externa que correspondia à era do capitalismo dos monopólios e dos oligopólios, como sublinhou Jean Bouvier ${ }^{26}$.

Charles V. Seignobos, em sua Histoire de la Civilisation, escrevia: "Os homens que povoam a terra... também diferem em língua, inteligência e sentimentos. Essas diferenças permitem dividir os habitantes da terra em vários grupos conhecidos como "raças'”. O manual de Langlois e Seignodos, bastante vulgarizado no mundo, pretendia alcançar objetividade e certeza histórica com base na confiança que lhes davam o método científico, o mesmo, possuía uma grande similaridade com os métodos das ciências naturais. No geral, esses historiadores "conseguiram alcançar boa reputação profissional, numa sociedade para cuja estabilidade contribuíram, prestando apoio a um consenso conservador, nacionalista e racista ${ }^{27}$. Com a aproximação cada vez mais patente das ciências com as esferas burocráticas estatais e políticas, os historiadores acadêmicos passaram a ter uma extrema dependência em relação ao poder, por vezes mostrava-se sem disfarce. “A compilação da história era considerada uma prerrogativa das autoridades, preocupadas sempre em difundir uma versão canônica ${ }^{28 "}$. Coligir, metodizar e guardar, eis o lema do IHGB - Instituto Histórico e Geográfico Brasileiro para a produção de um saber histórico voltado para a construção da história da nação. Lilia Moritz Schwarcz, em O espetáculo das raças ${ }^{29}$, apoiando-se nas reflexões do Jacques Le Goff, sustenta que, além do desejo de fundar uma historiografia nacional e original, havia a intenção de não só ensinar e divulgar conhecimentos, como formular uma história que, a exemplo dos demais modelos europeus, se dedicasse à exaltação e glória da pátria.

A afirmação dos estados nacionais favoreceu o crescimento das escolas históricas. "Cada forma de perfeição humana, é, num certo sentido, nacional e temporalizada, e, considerada de modo mais específico, individual ${ }^{30 ", ~ e n f a t i z a ~ H e l d e r, ~ c h a m a n d o ~ a t e n c ̧ a ̃ o ~ p a r a ~ a s ~}$ particularidades do indivíduo e das nações. O mundo das histórias nacionais de Ranke é um mundo europeu, observa Sérgio Buarque de Holanda, admirador confesso, que o considera o "pai da ciência da História ${ }^{31}$ ". Sérgio Buarque reconhece que na base da historiografia rankeana fora da Europa só existia o "caos e o cemitério ${ }^{32}$ ", e esta afirmação eurocentrica não era particular de Ranke, esta posição também estava presente entre os historiadores do seu tempo,

\footnotetext{
${ }^{26}$ Apud M’BOKOLO, Elikia. África Negra - História e Civilizações... Op. cit., p. 348.

${ }^{27}$ FONTANA, Josep. A história dos homens..., Op. cit.,p. 237.

${ }^{28}$ Idem, 2004, p. 239.

${ }^{29}$ SCHWARCZ, Lilia Moritz. O Espetáculo das Raças - cientistas, instituições e questão racial no Brasil (18701930). São Paulo: Companhia das Letras, 1993, p. 102.

${ }^{30}$ Apud BARROS, José D’Assunção. Historicismo: notas sobre um paradigma... Op. cit., p. 401.

${ }^{31}$ HOLANDA, Sérgio Buarque de. Ranke. São Paulo: Editora Ática, 1979, pp. 17-27.

${ }^{32}$ Idem, p. 29.
} 
tais como Macaulay, Michelet, Burckhardt. Nesse sentido as conexões e nexos dos outros povos com o mundo europeu constituía-se num verdadeiro "privilégio" ao compartilhar das experiências históricas europeias. Nesse sentido Hegel já havia lançado suas ideias fundadoras eurocentradas em A Razão da História, cuja preocupação em percorrer a história universal global, já evidenciava: “a única conexão essencial entre os negros e os europeus é a escravidão ${ }^{33}$ ". Por fim, Sérgio Buarque vê na divisão do trabalho historiográfico rankiano uma escolha que favoreceu os grupos políticos e sociais privilegiados, mas que "seguiu critérios e preferências próprios do tempo em que viveu ${ }^{34}$ ".

Os paradigmas da história científica no século XIX, ainda que apresente posições concorrenciais (historicismo e a escola metódica) estavam presos a uma concepção de sociedade como uma unidade orgânica, uma comunidade étnica, orientada por um valor transcendental, um universal abstrato onde a natureza humana se realiza, cujas resoluções teóricas era o da integração cultural de um povo enquanto nação.

A institucionalização da História no século XIX é correlata à fundação/invenção da nação. Os que advogavam a favor da profissionalização da história procuravam através de uma narrativa e uma marcante erudição escrever uma história nacional. "Mais que inventadas, nações são 'imaginadas', no sentido de que fazem sentido para a 'alma' e constituem objetos de desejos e projeções ${ }^{35}$ ". O historiador francês Guizot, ministro da Instrução de Luis Felipe (1832) dizia que a História deveria oferecer a nação sua ciência. Josep Fontana ${ }^{36}$ aponta que os intelectuais alemães trabalhavam, desde fim do século XVIII, para estabelecer as bases de uma cultura nacional calcada na unidade da língua. Apoiando-se na crítica cultural pós-colonial afirmamos que, "é a raça que efetivamente permite fundar, não apenas a diferença em geral, mas também a própria ideia de nação e de comunidade, uma vez que são os determinantes raciais que servem de base moral à solidariedade política ${ }^{37}$ ".

Essas novas concepções sobre o trabalho do historiador implicaram numa série de dificuldades para o desenvolvimento da investigação histórica no continente africano, principalmente no final do século XIX. Para além das intempéries de ordem econômica e política imposta pelo colonialismo e o imperialismo, temos os imperativos de ordem

\footnotetext{
${ }^{33} \mathrm{Hegel}$ entendia que a África em sua "inércia”, sem movimento, não teria tido grandes relações com a história universal. Essa citação de Hegel encontra-se em GILROY, Paul. O Atlântico Negro - modernidade e dupla consciência. São Paulo: Ed.34; Rio de Janeiro: Universidade Candido Mendes, Centro de Estudos Afro-Asiáticos, 2001, p. 101.

${ }^{34}$ HOLANDA, Sérgio Buarque de. Ranke... Op. Cit., 1979.

${ }^{35}$ ANDERSON, Benedict. Comunidades Imaginadas - reflexões sobre a origem e a difusão do nacionalismo. São Paulo: Companhia das Letras, 2008, p. 10.

${ }^{36}$ FONTANA, Josep. A história dos homens..., Op. cit., p. 221.

${ }^{37}$ MBEMBE, Achile. Crítica da razão negra. Lisboa: Antígona, 2014, p. 158.
} 
epistemológica. A história passa a ser encarada como uma atividade científica, por meio de análises rigorosas de fontes originais, para no limite, contribuir para a formação/consolidação do estado nação. Apesar de ser um modelo imitado no mundo todo, o método científico não era a única forma lícita de fazer história.

Nas primeiras décadas do século XX o historicismo encontra fortes opositores, fica estabelecida a sua crise, o econômico ganha cada vez mais espaço, assim como os conflitos de classe, ou seja, a questão social passa a ser um dos elementos centrais da pesquisa histórica que começa a enxergar a realidade em sua multiplicidade de práticas e de produção de fontes históricas. O progresso enquanto valor transcendental torna-se uma armadilha que os historiadores reconhecem como uma das antinomias da modernidade.

\section{DISSEMINAÇÃO DO HISTORICISMO E A (IM)POSSIBILIDADE DE UM CONHECIMENTO HISTÓRICO AFRICANO}

Vimos que no contexto da produção do paradigma historicista muitos historiadores assumiram posições particularmente conservadoras que visavam legitimar os estados nacionais, daqui por diante, serão analisados suas ligações, conexões e compromissos teóricos com a ideia de nação e seus governos, uma vez que, toda operação historiográfica se articula com o seu lugar de produção, como afirma Michel DeCerteau.

Paul Gilroy, em sua obra Entre Campos - nações, culturas e o fascínio da raça, reflete que na missão civilizadora do poder colonial e nas instituições jurídicas dos estados nação a raciologia foi inicialmente codificada e institucionalizada como um princípio de governo. Procuramos demonstrar em nossos estudos que os processos históricos das nações oitocentistas com suas expansões territoriais evidenciam os entrelaçamentos entre a "necessidade" de possessões e a racialização dos povos.

O historiador nigeriano Godfrey Uzoigwe especialista nos estudos da África Oriental, ao analisar as diferentes teorias sobre a partilha do continente africano, tema controverso e dominado inicialmente pelas explicações econômicas, observa que as teorias diplomáticas foram as que mais tiveram aceitação no ambiente acadêmico. Tais teorias apesar de serem puramente políticas "permitem ver os egoísmos nacionais dos Estados europeus 38 ".

Carlton Hayes ${ }^{39}$, defensor da teoria diplomática da partilha africana, apresenta um panorama geral da Europa em suas mobilizações expansionistas: a Franca procurava uma compensação para as perdas na Europa com ganhos no ultramar, enquanto o Reino Unido

\footnotetext{
${ }^{38}$ UZOIGWE, UZOIGWE, Godfrey N. Partilha européia e conquista da África: apanhado geral. In: História Geral da África, UNESCO, 2010, p. 26.

${ }^{39}$ Idem.
} 
aspirava compensar seu isolamento na Europa engrandecendo e exaltando o império britânico; a Rússia, bloqueada nos Balcãs, voltava-se de novo para a Ásia; a Alemanha e a Itália, queria mostrar ao mundo que tinham o direito de realçar seu prestigio, obtido a força na Europa por façanhas imperiais em outros continentes; Portugal e Holanda, demonstraram renovado interesse pelos impérios que já possuíam. Hayes conclui dizendo que, fundamentalmente, “o novo imperialismo era um fenômeno nacionalista" e que seus defensores tinham sede ardente de prestigio nacional. O historiador nigeriano Awason Bojang afirma que a empresa colonial foi sustentada por meio da articulação com a historiografia ao negar a historicidade, humanidade e capacidade de governo dos africanos ${ }^{40}$.

Vários critérios podiam definir o estatuto de uma nação. Ernest Renan já advertia sobre as possibilidades de existência de elementos objetivos comuns, tais como, os modos como os grupos humanos se definem ou são definidos como membros de uma nação num processo de autoidentificação. Ao priorizarmos os critérios étnicos e raciais na nossa abordagem, não queremos com isso reduzir a complexidade das formações nacionais a uma única dimensão. A raça foi um elemento concreto e subjetivo no fenômeno histórico da nação, em sua luta por unidade política e nacional. Raça e língua foram elementos definidores da nação. Vários autores que advogavam a favor dos postulados historicistas procuravam através de trabalhos históricos superar os enclaves linguísticos para construir um projeto de nação. As línguas vernáculas em suas complexas variações e multiplicidades locais precisavam ser "corrigidas" e unificadas, coube ao sistema educacional institucionalizado padronizar a língua nacional. A solidariedade nacional não era tão somente linguística. Os argumentos dos teóricos oitocentistas em prol da solidariedade consistiam em discursos do tipo: “todos nós somos uma única tribo, uma única família, somos um só sangue e uma só língua ${ }^{41}$ ”. A língua, explica Hobsbawm, no sentido herderiano, de ser falado pelo volk, sem dúvida não era diretamente um elemento central na formação do protonacionalismo, embora não lhe fosse necessariamente sem relevância ${ }^{42}$. Reconhecemos que a epistemologia historicista em suas conceituações e reflexões acerca do conhecimento histórico acumulado, e em seus métodos que procuravam apreender os fatos particulares para se integrarem nos quadros mais amplo do projeto nacional, até então estava em harmonia com a política de coesão das línguas nacionais e a formação do estado nação.

\footnotetext{
${ }^{40}$ Ver PANTOJA, Selma \& THOPSON, Estevam. As culturas africanas na encruzilhada do mundo. In: Selma Pantoja, Edvaldo A. Bergamo, Ana Cláudia da Silva (orgs.), África contemporânea em cena. Perspectivas interdisciplinares. São Paulo: Intermeios, 2015, p.80.

${ }^{41}$ HOBSBAWM, E. J. Nações e Nacionalismo desde 1870 - programa, mito, realidade. Rio de Janeiro: Editora Paz e Terra, 1990, p. 70.

${ }^{42}$ Idem, 1990, p.75.
} 
Quanto à etnicidade, era lugar comum afirmar as linhagens pela pureza de sangue, a ideia de raça era utilizada quase no mesmo sentido em que a palavra cultura é empregada hoje ${ }^{43}$. Portanto a abordagem genética da etnicidade não era desprovida de valor e sentido como base crucial na organização social. As doutrinas raciais do século XIX alimentadas pelas narrativas de viagens e fantasias das terras desconhecidas, "quando os povos selvagens passam a ser entendidos e caracterizados como primitivos ${ }^{44}$ " dividia-se entre os monogenistas e poligenistas. As raças humanas, enquanto "espécies diversas", deveriam ver na hibridação um fenômeno a ser evitado. O racismo é a matriz que permeia todos os domínios do imaginário do sistema mundial colonial/moderno ${ }^{45}$, resultado do longo processo de colonização.

Considerando que as circunstâncias em que os estados nações emergiram a partir de uma racionalidade racializada, queremos enfatizar o poder da raça como uma categoria explicativa para se compreender o desenvolvimento histórico e social do historicismo.

Iniciando-se na segunda metade do século XIX, a temática do sangue foi por vezes chamada a emprestar o seu inteiro peso histórico para revitalizar o tipo de poder político que se exercitava através dos dispositivos da sexualidade. O racismo tomou forma neste ponto (racismo em sua forma estadista, "biologizante", moderna): foi então que toda uma política de assentamento (povoamento), família, casamento, educação, hierarquização social, e propriedade, acompanhada por uma longa série de intervenções permanentes ao nível do corpo, conduta, saúde e vida cotidiana, recebeu a sua coloração e a sua justificação da preocupação mística com a proteção da pureza do sangue e com a garantia do triunfo da raça ${ }^{46}$.

\section{ORALIDADE E PENSAMENTO AFRICANO}

Tradição oral e memória são dois fenômenos indispensáveis aos estudos africanos, principalmente quando se refere à possibilidade de penetrar na história e no espírito dos povos que vivem/viverem nesse continente. Como seria possível construir um conhecimento histórico no século XIX onde a cultura escrita tinha precedência sobre a cultura oral? Só após a segunda guerra mundial essa hierarquia infundada começou a desmoronar. Amadou Hampaté Bâ apresenta em A tradição viva ${ }^{47}$ o poder da palavra falada nas tradições africanas, principalmente nas regiões em que pesquisou, a savana ao sul do Saara. A palavra falada possui um poder, uma

\footnotetext{
${ }^{43}$ GILROY, Paul. Entre Campos - nações, culturas e o fascínio da raça. Tradução de Célia Maria Marinho de Azevedo et ali. São Paulo: AnnaBlume, 2007, p. 43.

${ }^{44}$ SCHWARCZ, Lilia Moritz. O Espetáculo das Raças... Op. Cit., p. 44.

${ }^{45}$ MIGNOLO, Walter. A colonialidade de cabo a rabo: o hemisfério ocidental no horizonte conceitual da modernidade. LANDER, Edgardo. A Colonialidade do Saber -eurocentrismo e ciências sociais. Perspectivas latino-americanas. Colección Sur Sur, CLACSO, Ciudad Autónoma de Buenos Aires, Argentina, 2005, p.37.

${ }^{46}$ GILROY, Paul. Entre Campos... Op. cit., p. 92.

${ }^{47}$ HAMPATE-BÂ, A. A tradição viva. In: História Geral da África, vol. 1. São Paulo: Ática, 1982, pp. 181-218.
} 
força, um valor moral, um caráter sagrado e uma origem sagrada, que uma vez empossada em alguns agentes qualificados, desde que não utilizadas sem prudência, estavam encarregados da preservação e transmissão da memória. Contrariamente ao que o senso comum apregoa, a tradição oral africana não se limita a histórias e lendas, adverte Hampatebá, nem mesmo a relatos mitológicos ou históricos, a tradição oral era um modo de vida, uma grande escola da vida encarregada de recuperar e relacionar todos os aspectos da vida social. Para a tradição africana a fala é antes de tudo um dom de deus. "Ela é ao mesmo tempo divina no sentido descendente e sagrada no sentido ascendente ${ }^{48}$ ".

Maa Ngala, como se ensina, depositou em Maa as três potencialidades do poder, do querer o do saber, contidas nos vinte elementos dos quais ele foi composto. Mas todas essas forças, das quais é herdeiro, permanecem silenciadas dentro dele. Ficam em estado de repouso até o instante em que a fala venha coloca-las em movimento. Vivificadas pela Palavra divina, essas forças começam a vibrar. Numa primeira fase, tornam-se pensamento; numa segunda som; e numa terceira, fala. A fala é portanto, considerada como a materialização, ou a exteriorização, das vibrações de força ${ }^{49}$."

Essa complexa dinâmica cosmológica que relaciona elementos humanos e não humanos não atendia ao refinamento conceitual da tradição metafísica moderna, hoje a antropologia pósestruturalista reconhece que o fato social não é produzido apenas entre os humanos. Diante desse aspecto transcendente e metafisico, como o conhecimento histórico africano poderia ser apreendido pelos fundamentos metodológicos desta consciência histórica eurocêntrica oitocentista.

O tempo histórico em sua complexidade é o lugar onde diferentes períodos e diferentes mentalidades sobrepõem-se, produzindo uma dinâmica particular. Nas sociedades africanas, humanos e animais estavam ligados a uma sociabilidade comum. Na África pré-colonial tudo é história, a história da vida compreende a história das terras e das águas, a história dos vegetais, a história dos minérios e metais, a história dos astros, das águas. Não havia uma contradição entre natureza e cultura, os humanos são organismos como os outros, corpos-objetos em interação com outros corpos e forças.

\footnotetext{
${ }^{48}$ Idem, 1982.

${ }^{49}$ Hampaté Bâ nasceu em 1900, exatamente no ano final do século XIX. Em sua fase mais madura, então como etnólogo, relata que muitos mestres tradicionalistas frequentavam a casa do seu pai. O seu pai viu de perto as primeiras perseguições do poder colonial para extirpar as tradições locais. "A corte de meu pai foi praticamente reconstruída, e tradicionalistas chegavam de todos os países, para se reunir em sua casa..." O africano da savana, informa Hampaté Bâ, viajava muito, o resultado era a troca e a circulação de conhecimentos, é por esse motivo que a memória histórica coletiva da África raramente se limita a um único território. Ele reuniu um conjunto significativo de narrativas, utilizando o método da gravação e em seguida comparava as narrações no sentido de controlar e verificar a veracidade, um trabalho de fôlego, com viagens de Guiné a Nigéria, que exigiu mais de 15 anos de trabalho e uma coleta de hum mil relatos orais. Todos os testemunhos atestaram a experiência do passado em suas condições concretas. "Essa experiência provou-me que a tradição oral era perfeitamente válida do ponto de vista científico." (1982, pp. 181-218).
} 
Procurando responder as injunções e ao mesmo tempo apresentar uma história endógena do continente africano, surge na segunda metade do século XIX na África sul-saariana, uma intelectualidade que procura desconstruir por meio de elaboradas reflexões as representações de uma África como o "fardo do homem branco". Apresentam novas bases dos estudos africanos que irão denunciar as cumplicidades entre a razão e a raça. Esse surgimento de um pensamento africano está representado nas figuras de Pierre-David Boilat, Samuel Crowther, James Johnson, JamesAfricanus Horton, Edward Wilmot Blyden, Alexandrer Crummell, OliveSchreiner, Tiyo Soga, Walter Rubusana, John T. Jabavu, Stephanus JacobusDu Toit, José F. Pereira, Paulo A. Braga, entre outros.

A exposição dessa cartografia de pensamentos ocidentais e não-ocidentais revelam assimetrias e hierarquias geopolíticas, assim como o lugar periférico de uma intelectualidade que pensava suas culturas dentro dos seus próprios termos ou cosmovisões ancestrais. Esse desafio é enfrentado por intelectuais ${ }^{50}$ que produziam textos escritos elaborados com a finalidade combater, expressar ou interpretar a posição de subalternidade presentes nas construções ideológicas do pensamento europeu. Eduardo Deves-Valdés em O pensamento africano subsaariano ${ }^{51}$ afirma que o principal tema, senão o mais compartilhado pelos pensadores africanos da segunda metade do século XIX, era a Civilização. Samuel Johnson, James Africanus Norton e Edward Blyden são alguns dos intelectuais que elegeram esse tema como mediador de suas construções discursivas para análise do continente africano e do atlântico negro. Para Paul Gilroy, parte dessa intelectualidade do atlântico negro absorve o pensamento romântico europeu apontando para outro caminho.

Como o conceito de civilização, o chauvinismo racial pode ser remontado aos escritos de Hegel, Guizot, Gobineau e outros teóricos raciais do continente do século XIX. De fato, foi o alemão Herder, que no século XVIII, desenvolveu teorias de coletivismo orgânico, a partir das quais Blyden e Crummel mais tarde elaboraram sua própria variedade de chauvinismo étnico ${ }^{52}$.

Esses pensadores iniciaram uma tradição de produção científica que procuravam reafirmar a existência de civilizações complexas por todo o continente africano, rejeitando assim o particularismo europeu caracterizado como universal.

\footnotetext{
${ }^{50}$ Por trabalho historiográfico não fiz o entendimento de que somente às obras de história escritas por "historiadores profissionais", com formação específica em história, haja vista que não existia até a meados do século XX instituições acadêmicas voltadas para tal fim, poderiam interpretar o processo histórico.

${ }^{51}$ DEVES-VALDES, Eduardo. O pensamento africano subsaariano - conexões e paralelos com o pensamento pensamento latino-americano e o asiático (um esquema). São Paulo: CLASCSO, EDUCAM, 2008.

52 GILROY, P. O atlântico negro - modernidade e dupla consciência. São Paulo: Editora 34; Rio de Janeiro: Universidade Cândido Mendes, Centro de Estudos Afro-asiáticos, 2001, p.299.
} 
É surpreendente que o historiador alemão Johann G. Herder ao contribuir teoricamente para a construção da noção de tempo histórico, apresentando os diferentes tempos que o compõe (como veremos na citação abaixo), opondo-se as generalizações, as ideias de civilização ocidental, ao apresentar pesquisas sobre as diferentes particularidades dos grupos humanos e desenvolver uma concepção de cultura como "expressão do espírito de um povo", paradoxalmente defendia a existência de "estágios da cultura", "progressos da cultura".

Na verdade, cada coisa [Ding] capaz de se modificar traz em si a própria medida de seu tempo; essa medida continua existindo, mesmo se não houver mais nenhuma outra ali; não há duas coisas no mundo que tenham a mesma medida de tempo (...) Pode-se afirmar, portanto, com certeza e também com alguma audácia, que há, no universo, a um mesmo e único tempo, um número incontável de outros tempos ${ }^{53}$.

\section{À GUISA DE CONCLUSÃO}

Em um trabalho que procurou analisar a historiografia africana, Carlos Lopes ${ }^{54}$, em A pirâmide invertida - historiografia africana, reconhece que "o produto historiográfico não tem nenhuma independência ou autonomia, depende inteiramente do momento e ideologia que influenciam a sua concepção".

As teorias enquanto representação discursiva de processos históricos concretos são construções particulares, mediadas por experiências particulares. A Alemanha, entre outros países europeus, vivenciou a experiência da modernização, das tensões entre em sua fase de desenvolvimento industrial e seus vínculos com a tradição, dos conflitos de unificação e os projetos de afirmação nacional, a consolidação da história-disciplina estava no amplo espectro das teorias modernizadoras. Não queremos afirmar sob hipótese alguma que elas não são necessárias, as teorias são abrangentes e tratam da construção narrativa de fenômeno concretos, procurando explicar apenas no que tenha em comum com os fenômenos semelhantes, o seu caráter abstrato de revela também como possibilidade de revelar outros fenômenos particulares.

Os intelectuais europeus conservaram a ilusão de que a cultura europeia foi, de fato e por direito, uma cultural universal. Procuramos demonstrar que o lócus de enunciação do historicismo estava marcado por sua localização geopolítica dentro do sistema mundial moderno/colonial e pelas hierarquias raciais.

É justamente no exercício contínuo desse olhar sobre si, ou seja, a prática da análise crítica que a geração de historiadores profissionais do século XX fizeram sobre o seu próprio

\footnotetext{
${ }^{53}$ KOSELLECK, Reinhart. Futuro Passado... Op. cit., p. 14.

54 LOPES, Carlos. A Pirâmide Invertida - historiografia africana feita por africanos. In Actas do Colóquio Construção e ensino da história da África. Lisboa: Linopazes, 1995, p. 28.
} 
trabalho de historiador, "desmascarando interesses específicos que as tenha levado a produzir uma visão histórica e não outra ${ }^{55 ",}$, que permite-nos apontarmos os atravessamentos raciológicos presentes nas escolas históricas oitocentistas.

Recebido em: 29/04/2018

Aceito em: 11/07/2018

\section{REFERÊNCIAS BIBLIOGRÁFICAS}

BARBOSA, Muyratan Santana. A África por ela mesma: a perspectiva africana na História Geral da África (Unesco). Tese de Doutorado. São Paulo: Faculdade de Filosofia, Letras e Ciências Humanas da Universidade de São Paulo, 2012.

ANDERSON, Benedict. Comunidades Imaginadas - reflexões sobre a origem e a difusão do nacionalismo. São Paulo: Companhia das Letras, 2008.

BARROS, José D’Assunção. Historicismo: notas sobre um paradigma. Revista Antítese, v.5, n. 9 pp. 391-419, jan/jul, 2012.

BARRY, Boubacar. Senegâmbia: o desafio da história regional. Rio de Janeiro: SEPHISCentro de Estudos Afro-Asiáticos da Universidade Candido Mendes, 2000.

CERTEAU, Michel de. A escrita da história. Rio de Janeiro: Forense Universitária, 1982.

DEVES-VALDES, Eduardo. O pensamento africano subsaariano - conexões e paralelos com o pensamento latino-americano e o asiático (um esquema). São Paulo: CLASCSO, EDUCAM, 2008.

DOSSE, François. A História. São Paulo: Editora Unesp, 2012.

FAGE, J. D. A evolução da historiografia da África. In: História Geral da África, vol. 1. São Paulo: Ática, 1982.

FONTANA, Josep. A história dos homens. São Paulo: Edusc, 2004.

GILROY, Paul. Entre Campos - nações, culturas e o fascínio da raça. Tradução de Célia Maria Marinho de Azevedo et ali. São Paulo: AnnaBlume, 2007.

O atlântico negro - modernidade e dupla consciência. São Paulo: Ed. 34; Rio de Janeiro: Ed. Universidade Candido Mendes, Centro de Estudos AfroAsiáticos, 2001.

HAMPATE-BÂ, A. A tradição viva. In: História Geral da África, vol. 1. São Paulo: Ática, 1982.

HOFBAUER, Andreas. História de branqueamento ou o negro em questão. São Paulo: Editora Unesp, 2007.

HOLANDA, Sérgio Buarque de. Ranke. São Paulo: Editora Ática, 1979.

${ }^{55}$ BARROS, José D’Assunção. Historicismo: notas sobre um paradigma... Op. cit., p. 399. 
KI-ZERBO, J. O lugar da história na sociedade africana. In: História Geral da África, vol. 1. São Paulo: Ática, 1982.

KOSELLECK, Reinhart. Futuro Passado - contribuição à semântica dos tempos históricos. Rio de Janeiro: Editora Contraponto; Editora PUC-Rio, 2006.

HORKHEIMER. M. \& ADORNO. T. Dialética do Esclarecimento. Rio de Janeiro: Jorge Zahar, 1985.

HOBSBAWM, E. J. Nações e Nacionalismo desde 1870 - programa, mito, realidade. Rio de Janeiro: Editora Paz e Terra, 1990.

LOPES, Carlos. A Pirâmide Invertida - historiografia africana feita por africanos. In: Actas do Colóquio Construção e ensino da história da África. Lisboa: Linopazes, 1995.

MBEMBE, Achile. Crítica da razão negra. Lisboa: Antígona, 2014.

MIGNOLO, Walter. A colonialidade de cabo a rabo: o hemisfério ocidental no horizonte conceitual da modernidade. In: LANDER, Edgardo. A Colonialidade do Saber -eurocentrismo e ciências sociais. Perspectivas latino-americanas. Colección Sur Sur, CLACSO, Ciudad Autónoma de Buenos Aires, Argentina, 2005.

M'BOKOLO, Elikia. África Negra - História e Civilizações. Tradução de Alfredo Margarido. Salvador: EDUFBA; São Paulo: Casa das Áfricas, 2009.

PANTOJA, Selma. As culturas africanas na encruzilhada dos mundos. In: África contemporânea em cena: perspectivas interdisciplinares. Brasília: Intermeios, 2015.

PRATT, Mary Louise. Os olhos do império: relatos de viagem e transculturação. Bauru (SP): EDUSC, 1999.

SAID, Edward. Cultura e imperialismo. São Paulo: Companhia das Letras, 2011.

SCHAFF, Adam. História e Verdade. São Paulo: Martins Fontes, 1983.

SCHWARCZ, Lilia Moritz. O Espetáculo das Raças - cientistas, instituições e questão racial no Brasil (1870-1930). São Paulo: Companhia das Letras, 1993.

RÜSEN, J. Razão Histórica - teoria da história: os fundamentos da ciência histórica. Brasília: Editora da Universidade de Brasília, 2011.

UZOIGWE, Godfrey N. Partilha européia e conquista da África: apanhado geral. In: História Geral da África. Brasília: Unesco, 2010. 